\title{
Overexpression of Protein Kinase M $\zeta$ in the Prelimbic Cortex Enhances the Formation of Long-Term Fear Memory
}

\author{
Yan-Xue Xue ${ }^{1,6}$, Zhen-Zhen Zhu ${ }^{2,3,6}$, Hai-Bin Han ${ }^{2,3}$, Jian-Feng Liu, ${ }^{1,4,5}$, Shi-Qiu Meng ${ }^{1,4,5}$, Chen Chen ${ }^{1,4,5}$, \\ Jian-Li Yang ${ }^{*, 2,3}$, Ping $\mathrm{Wu}^{*, 1}$ and Lin Lu*, I,4,5 \\ 'National Institute on Drug Dependence and Beijing Key Laboratory of Drug Dependence, Peking University, Beijing, China; ${ }^{2}$ Tianjin Medical \\ University, Tianjin, China; ${ }^{3}$ Center of Tianjin Mental Health Center, Tianjin, China; ${ }^{4}$ Institute of Mental Health/Peking University Sixth Hospital and \\ Key Laboratory of Mental Health, Beijing, China; ${ }^{5}$ Peking-Tsinghua Center for Life Sciences and PKU-IDG/McGovern Institute for \\ Brain Research, Peking University, Beijing, China
}

\begin{abstract}
Neuroplasticity in the prefrontal cortex (PFC) after fear conditioning has been suggested to regulate the formation and expression of fear memory. Protein kinase $M \zeta(P K M \zeta)$, an isoform of protein kinase $C$ with persistent activity, is involved in the formation and maintenance of memory. However, less is known about the role of PKM $\zeta$ in the PFC in the formation of fear memory. We investigated whether the overexpression of PKM $\zeta$ enhances the formation of auditory fear memory in rats. We found that microinfusion of lentiviral vectorexpressing PKM $\zeta$ into the prelimbic cortex (PrL) selectively enhanced the expression of PKM $\zeta$ without influencing the expression of other isoforms of PKC. The overexpression of PKM $\zeta$ in the PrL enhanced the formation of long-term fear memory without affecting short-term fear memory, whereas the overexpression of PKM $\zeta$ in the infralimbic cortex had no effect on either short-term or long-term fear memory. The overexpression of PKM $\zeta$ in the PrL had no effect on anxiety-like behavior or locomotor activity. We also found that PKM $\zeta$ overexpression potentiated the fear conditioning-induced increase in the membrane levels of glutamate subunit 2 of AMPA receptors in the PrL. These results demonstrate that the overexpression of PKM $\zeta$ in the PrL but not infralimbic cortex selectively enhanced the formation of long-term fear memory, and PKM $\zeta$ in the PrL may be involved in the formation of fear memory.

Neuropsychopharmacology (20I5) 40, 2I46-2156; doi:I0.1038/npp.20I5.56; published online 25 March 2015
\end{abstract}

\section{INTRODUCTION}

Fear normally causes individuals to generate an adaptive response to danger, whereas extreme fear and anxiety can become harmful and maladaptive and lead to fear and anxiety disorders, such as posttraumatic stress disorder (LeDoux, 2000; Maren et al, 2013). Thus, a deeper understanding of the neurobiological mechanisms of fear memory has significant clinical implications and may aid in the development of more effective therapies for amnesia, cognitive decline, or fear and anxiety disorders (Duvarci and Pare, 2014; Maren and Quirk, 2004). In animal studies, the mechanisms that underlie fear can be investigated using Pavlovian fear conditioning, in which an originally neutral conditioned stimulus (CS; eg, a tone) is paired with an aversive unconditioned stimulus [US; eg, a shock; (LeDoux 2000; Maren and Quirk 2004)].

* Correspondence: Professor J-L Yang, Tianjin Mental Health Center, 13, Liu Lin Road, Tianjin 300222, China, Tel: +86 22 88।88005, Fax: +86 22 88188818, E-mail: yangjianli0722@sohu.com or Dr P Wu, National Institute on Drug Dependence, Peking University, 38, Xue Yuan Road, Beijing 100191, China, Tel: +86 10 82802456, Fax: +86 1062032624 , E-mail: wuping@bjmu.edu.cn or Professor L Lu, Institute of Mental Health, Peking University, 5 I, Huayuan Bei Road, Beijing I00 I9I, China, Tel: +86 10 82805308, Fax: +86 10 62032624, E-mail: linlu@bjmu.edu.cn

${ }^{6}$ These authors contributed equally to this work.

Received 7 October 2014; revised 29 January 2015; accepted 24 February 2015; accepted article preview online 27 February 2015
The medial prefrontal cortex (mPFC) is a neocortical structure that can be cytoarchitectonically divided into different subregions, including the prelimbic cortex (PrL) and infralimbic cortex (IL; Heidbreder and Groenewegen, 2003). Although most studies have focused on the role of the amygdala and hippocampus in fear memory (Bannerman et al, 2004; Duvarci and Pare, 2014; Fanselow and Gale 2003; Goosens 2011; Maren 2003; Riccio and Joynes 2007), a growing body of evidence demonstrates that the mPFC has an important role in modulating the formation, expression, and extinction of fear (Gilmartin et al, 2014; Quirk and Beer, 2006a; Sotres-Bayon and Quirk, 2010). For example, reducing $\mathrm{mPFC}$ activity, blocking the signaling pathways of the dopamine $\mathrm{D}_{1}$ receptor and $N$-methyl-D-aspartate (NMDA) receptor, and ubiquitin-proteasome system-mediated protein degradation in the mPFC disrupted the formation of trace or delayed fear conditioning (Gilmartin and Helmstetter, 2010; Reis et al, 2013; Runyan and Dash, 2004). Different subregions of the mPFC appear to have distinct functions in fear memory, and the IL appears to control extinction learning, in which a new conditioned stimulus-no unconditioned stimulus association is formed (Milad and Quirk 2002; Milad et al, 2007; Peters et al, 2010; Quirk et al, 2006b). The PrL was found to modulate the expression of learned fear (Corcoran and Quirk, 2007; Guhn et al, 2014; Lee and Choi, 2012; Sotres-Bayon et al, 2012; Vidal-Gonzalez et al, 2006). Recently, the PrL has also been 
suggested to participate in the storage of fear memory. NMDA receptor blockade or perineuronal net disruption in the PrL impaired the storage of learned fear in rats (Gilmartin and Helmstetter, 2010; Hylin et al, 2013).

Protein kinase $\mathrm{M} \zeta(\mathrm{PKM} \zeta)$ is a brain-specific protein kinase $\mathrm{C}(\mathrm{PKC})$ isoform with persistent activity (Sacktor 2008). In the past few years, $\mathrm{PKM} \zeta$ has been found to be critical for the maintenance of long-term potentiation (LTP) and long-term memories (Pastalkova et al, 2006; Sacktor 2008). Microinfusion of the PKC $\zeta$ inhibitory peptide ZIP abolished the maintenance of various types of long-term memories, including hippocampus-dependent spatial learning (Pastalkova et al, 2006), amygdala-dependent auditory fear conditioning (Serrano et al, 2008), insular cortexdependent conditioned taste aversion (Shema et al, 2007), and nucleus accumbens-and amygdala-dependent drugassociated memories (He et al, 2011; Li et al, 2011). Evuarherhe et al, (2014) found that $\mathrm{PKM} \zeta$ in the medial PFC may be involved in the formation of recognition memory. The underlying mechanisms of $\mathrm{PKM} \zeta$ in memory regulation may involve the glutamate subunit 2 trafficking of $\alpha$-amino-3-hydroxy-5-methyl-isoxazole-4-propionic acid receptors (GluA2; (Migues et al, 2010; Yao et al, 2008). However, in these studies, the chemical compound that was used to modulate PKM $\zeta$ activity was ZIP, the specificity of which for $\mathrm{PKM} \zeta$ has been challenged (Kwapis and Helmstetter, 2014). ZIP has been shown to suppress the activity of $\mathrm{PKCl} / \lambda$ (Ren et al, 2013a), and the application of ZIP in PKC $\zeta$ knockout mice abolished the maintenance of LTP and long-term memory (Lee et al, 2013; Volk et al, 2013). Using viral transfection of the insular cortex to selectively modulate the expression of $\mathrm{PKM} \zeta$, Shema et al, (2011) found that $\mathrm{PKM} \zeta$ overexpression enhanced the memory trace of conditioned tasted aversion, whereas dominant-negative $\mathrm{PKM} \zeta$ overexpression disrupted memory, even long after the memory was formed. Inspired by these studies, using a lentiviral vector-expressing $P K M \zeta$ gene, we investigated whether the overexpression of $\mathrm{PKM} \zeta$ in the mPFC enhances the formation of auditory fear memory.

\section{MATERIALS AND METHODS}

\section{Subjects}

All of the experiments were performed according to the National Institutes of Health Guide for the Care and Use of Laboratory Animals and Biomedical Ethics Committee of Peking University for animal use and protection. Male Sprague-Dawley rats (3-month old, 200-220 g) were obtained from the Laboratory Animal Center, Peking University Health Science Center. These rats were housed five per cage with ad libitum access to food and water under a $12 \mathrm{~h} / 12 \mathrm{~h}$ light/dark cycle. The behavioral experiments were conducted during the dark phase of the cycle.

\section{Design, Construction, and Validation of Lentiviral Vectors for PKM $\zeta$ Overexpression}

The construction and use of the lentiviral vectors were based on our previous studies with minor modifications (Zhu et al, 2012). pSinRep5-pPKM $\zeta$-Ires-ZsGreen vector plasmids (kindly provided by Todd Sacktor, SUNY Downstate
Medical Center, Brooklyn, NY, USA) were constructed for the production of lentiviruses that express $\mathrm{PKM} \zeta$. $\mathrm{PKM} \zeta$ was amplified by PCR from the vectors and subcloned into the GV208 vector using BamHI and AgeI restriction sites. All of the vectors contained the enhanced green fluorescence protein (eGFP) coding sequence, and $\mathrm{PKM} \zeta$ was separated from eGFP by IRES. All of the vectors were then transfected into human embryonic kidney 293 cells. Approximately $48 \mathrm{~h}$ post-transfection,

cells were collected, purified by centrifugation, and stored at $-80^{\circ} \mathrm{C}$ (Genechem, Shanghai, China).

\section{Surgery}

The rats were anesthetized with sodium pentobarbital $(50 \mathrm{mg} /$ $\mathrm{kg}$, ip) and then placed in a stereotaxic apparatus. Identical stainless-steel guide cannulae (22 gauge) were bilaterally implanted into the IL (anterior/posterior, $+2.9 \mathrm{~mm}$; medial/ lateral, $\pm 2.3 \mathrm{~mm}$; dorsal/ventral, $-4.8 \mathrm{~mm}$ ) and PrL (anterior/ posterior, $+2.9 \mathrm{~mm}$; medial/lateral, $\pm 2.3 \mathrm{~mm}$; dorsal/ventral, $-3.0 \mathrm{~mm}$; (He et al, 2011; Paxinos and Watson, 2005). The cannulae were placed at a $16^{\circ}$ angle toward the midline to avoid penetration of the lateral ventricle. After surgery, the rats were allowed 7 days to recover, during which time they were handled until the start of training.

\section{Intracerebral Injections of Lentiviruses and Drugs}

The experimental parameters that were used for the virus injections were based on previous work from our and other laboratories (Shema et al, 2011; Zhu et al, 2012). The $\mathrm{LV}_{\mathrm{PKM} \zeta \text {-GFP }}$ and $\mathrm{LV}_{\mathrm{GFP}}$ lentiviruses $\left(1 \times 10^{9}\right.$ viral genomes, dissolved in phosphate-buffered saline (PBS)) were injected into the IL or PrL with $10 \mu \mathrm{l}$ Hamilton syringes that were connected via polyethylene-50 tubing to 30-gauge injectors. The Hamilton syringes were connected to an infusion pump (World Precision Instruments, Sarasota, FL, USA). The viruses were delivered bilaterally over $10 \mathrm{~min}$ at an infusion rate of $0.1 \mu \mathrm{l} / \mathrm{min}$ (total volume, $1 \mu \mathrm{l}$ per side), and the injectors were left in place for an additional $2 \mathrm{~min}$ to allow diffusion before removing them. At the end of the experiments, the rats were anesthetized with sodium pentobarbital (100 mg/kg, ip) and transcardially perfused. Cannula placements were assessed using Nissl staining with a section thickness of $40 \mu \mathrm{m}$ under light microscopy. Rats with misplaced cannulae were excluded from the statistical analysis.

\section{Apparatus and Procedures}

Apparatus. Fear conditioning was conducted using a video-based fear system (Beijing Macro Ambition S\&T Development, Beijing, China) as in our previous study (Yang et al, 2013). The system consists of four Plexiglas chambers ( $30 \mathrm{~cm}$ height $\times 30 \mathrm{~cm}$ width $\times 30 \mathrm{~cm}$ length) with floors made of metal stainless-steel rods connected to a shock generator. Each chamber was enclosed within a ventilated acoustic isolation box. Across the experiments, two different contexts (A and B) were used. Context A consisted of a chamber with a grid floor and was illuminated by a white light. Context A (conditioning context) consisted of the original conditioning chamber with a $20 \%$ ethanol odor. In context B, several modifications were introduced based on 
the original training chambers to create a novel testing context. In context $\mathrm{B}$, the stainless-steel rod floor and rear walls were covered with black Plexiglas, and a $2 \%$ acetic acid odor was introduced.

Training. The fear-conditioning procedure was conducted based on methods used in previous studies from our and other laboratories with minor modifications (Monfils et al, 2009; Si et al, 2012; Yang et al, 2013). The animals were placed into training chamber A and allowed to explore it for $10 \mathrm{~min}$. Fear conditioning was then conducted with three $20 \mathrm{~s}, 2 \mathrm{kHz}, 80 \mathrm{~dB}$ tones (CS), each coterminating with a $1 \mathrm{~s}$, $0.75 \mathrm{~mA}$ footshock (US). The interval between each CS was an average of $120 \mathrm{~s}$. After conditioning, the rats were allowed to explore the conditioning chamber for an additional $1 \mathrm{~min}$ before being returned to its home cage.

Test. During the long-term memory tests, the rats were first placed in the test chamber (context B) for 2 min to determine pre-CS freezing behavior. The test sessions consisted of three presentations of the CS with a CS-CS interval of $120 \mathrm{~s}$. The rats were returned to their home cage $120 \mathrm{~s}$ after the last CS. The data represent the average of the two trials.

Behavioral score. Behavioral scores were recorded and analyzed using computer software (Beijing MacroAmbition S\&T Development, Beijing, China) by an experimenter who was blind to the treatment. Conditioned fear was assessed by measuring the percentage of time spent freezing during the 20 -s period of each CS presentation. Freezing behavior was measured using an animal behavior video analysis system (Beijing MacroAmbition S\&T Development, Beijing, China).

Locomotor activity. Locomotor activity was assessed based on our previous studies (Shi et al, 2012; Zhu et al, 2012). Briefly, the open-field apparatus consisted of a $75 \times 75 \times 40 \mathrm{~cm}$ square arena that was divided into 25 equal squares $(15 \times 15 \mathrm{~cm})$ on the floor. Each rat was placed in the center of the apparatus, and the number of crossings into adjacent squares was counted for $5 \mathrm{~min}$ to assess locomotor activity.

Elevated plus maze. The elevated plus maze test was based on our previous studies (Suo et al, 2013). Briefly, each rat was first placed in the central zone of the elevated plus maze. The rat was allowed to freely explore the maze for $5 \mathrm{~min}$, and the entire test was conducted under dim illumination. The number of entries into and time (in seconds) spent on the open arms were recorded by two independent observers who were blind to the animal groups and sat quietly $2.5 \mathrm{~m}$ from the maze.

\section{Tissue Sample Preparation}

Tissue samples were prepared based on our previous studies (Ren et al, 2013b; Xue et al, 2014). After the behavioral experiments, the rats were decapitated, and the brains were rapidly extracted and frozen in $-40^{\circ} \mathrm{C} \mathrm{N}$-hexane. The brains were then stored in $\mathrm{a}-80^{\circ} \mathrm{C}$ freezer. Bilateral tissue punches (12 gauge) of the PrL and IL were then taken. Afterward, each tissue punch was exposed to $100 \mu$ of radioimmunoprecipitation assay (RIPA) lysis buffer (20 mM Tris ( $\mathrm{pH} 7.5)$,
$150 \mathrm{mM} \mathrm{NaCl}, 1 \%$ Triton X-100, $2.5 \mathrm{mM}$ sodium pyrophosphate, $1 \mathrm{mM}$ EDTA, $1 \% \mathrm{Na}_{3} \mathrm{VO}_{4}, 0.5 \mathrm{~g} / \mathrm{ml}$ leupeptin, and $1 \mathrm{mM}$ phenylmethanesulfonyl fluoride; Beyotime Biotechnology) for $30 \mathrm{~min}$. The tissue samples were then homogenized (10-15 s three times at 5-s intervals) with an electrical disperser (Wiggenhauser). The tissue homogenates were then subjected to $10000 \times g$ centrifugation at $4^{\circ} \mathrm{C}$ for $20 \mathrm{~min}$. The supernatant was used for subsequent western blot. The membrane fractions were prepared using a membrane protein extraction kit (Applygen, Beijing, China). The protein concentrations of all of the samples were determined using the bicinchoninic acid assay (Beyotime Biotechnology). The samples were further diluted in RIPA lysis buffer to equalize the protein concentrations.

\section{Western Blot Assays}

The western blot assays were based on our previous studies (Xue et al, 2012; Xue et al, 2014). Loading buffer $(5 \times ; 16 \%$ glycerol, $20 \%$ mercaptoethanol, $2 \%$ sodium dodecyl sulfate (SDS), and $0.05 \%$ bromophenol blue) was added to each sample ( $4: 1$, sample:loading buffer) before boiling for $3 \mathrm{~min}$. The samples were cooled and subjected to SDSpolyacrylamide gel electrophoresis (10\% acrylamide/ $0.27 \%$ $N, N^{\prime}$-methylenebisacrylamide resolving gel) for $\sim 40 \mathrm{~min}$ at $80 \mathrm{~V}$ in stacking gel and $\sim 1 \mathrm{~h}$ at $120 \mathrm{~V}$ in resolving gel. Proteins were electrophoretically transferred to polyvinylidene fluoride transfer membranes (Millipore, Bedford, MA, USA) at $0.25 \mathrm{~A}$ for $2.5 \mathrm{~h}$. Membranes were washed with TBST (tris-buffered saline plus $0.05 \%$ Tween-20, pH 7.4) and then dipped in blocking buffer (5\% bovine serum albumin (BSA) in TBST) overnight at $4^{\circ} \mathrm{C}$. The next day, the membranes were incubated for $1 \mathrm{~h}$ at room temperature on an orbital shaker with anti-PKC $\zeta$ antibody $(1: 1000$; Santa Cruz Biotechnology, Santa Cruz, CA, USA; catalog no. sc216), anti-PKC $\alpha$ antibody (1:1000; Santa Cruz Biotechnology; catalog no. sc-208), anti-PKC $\lambda$ antibody (1:1000; Santa Cruz Biotechnology; catalog no. sc-11399), anti-GluA1 antibody (1:1000; Abcam, Cambridge, UK; catalog no. ab109450), anti-GluA2 antibody (1:1000; Abcam; catalog no. ab52932), anti-GluA3 antibody (1:1000; Abcam, catalog no. ab40845), anti-Na-K ATPase antibody ( $1: 1000$; Abcam, catalog no. ab7671), or $\beta$-actin $(1: 1000 ;$ Santa Cruz Biotechnology; catalog no. sc-47778) in TBST plus 5\% BSA and $0.05 \%$ sodium azide. After three 5 -min washes (three times) in TBST buffer, the blots were incubated for $45 \mathrm{~min}$ at room temperature on a shaker with horseradish peroxidaseconjugated secondary antibody (goat anti-rabbit IgG for $\mathrm{PKC} \alpha, \mathrm{PKC} \lambda, \mathrm{PKM} \zeta$, GluA1, GluA2, and GluA3; goat antimouse IgG for $\beta$-actin and $\mathrm{Na}-\mathrm{K}$ ATPase Santa Cruz Biotechnology) diluted 1:5000 in blocking buffer. The blots were then washed three times for $5 \mathrm{~min}$ each in TBST and incubated with a layer of Super Signal Enhanced chemiluminescence substrate (Detection Reagents 1 and 2, 1:1 ratio, Pierce Biotechnology, Rockford, IL, USA) for $1 \mathrm{~min}$ at room temperature. Excess mixture was dripped off before the blots were wrapped with a clean piece of plastic wrap (no bubbles between blot and wrap), and the blots were then screened using the ChemiDoc MP System (BioRad, Hercules, CA, USA) for 5-60 s. The band intensities for PKM $\zeta$ were quantified by two observers who were blind to the experimental groups using Quantity One 4.4.0 software 
a

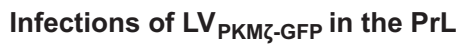
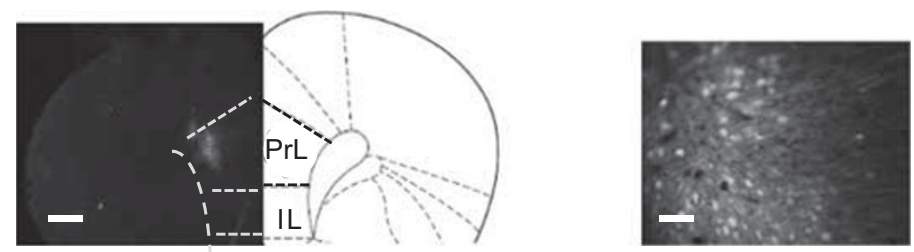

b

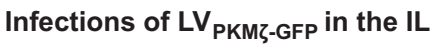
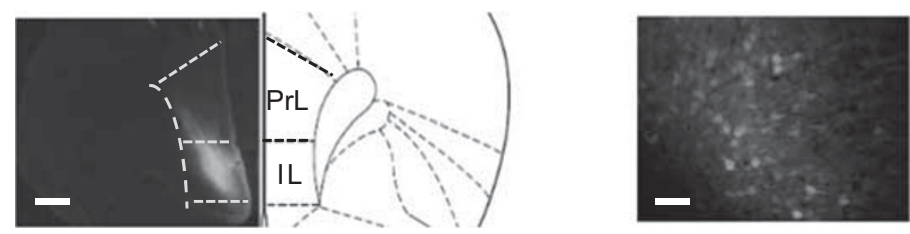

c

Protein expression of PKC isoforms in the PrL

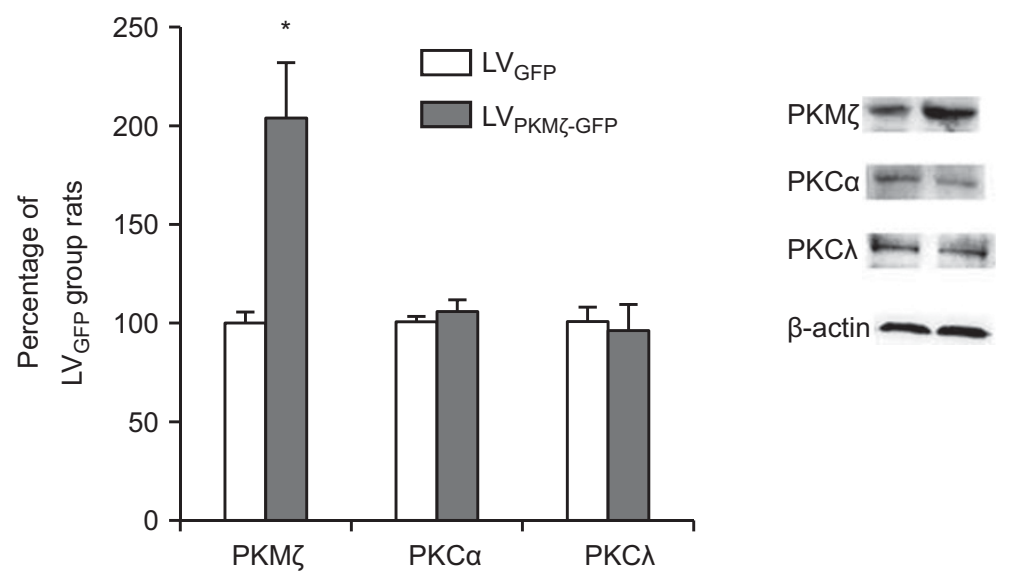

Figure I Lentiviral PKM -GFP infection in the PrL enhances the expression of PKM $\zeta$ but not other isoforms of PKC in the PrL. (a, b) Representative pictures of the injection sites and coronal sections of the rat brain with LV PKM -GFP infusion into the PrL and IL. Scale bars, $500 \mu \mathrm{m}$ (low-power images) and $50 \mu \mathrm{m}$ (high-power images). (c) Western blot with an PKM antibody that depicts a significant increase in PKM $\mathrm{C}$ expression in the PrL after infusion of a lentiviral vector that contained the PKM $\zeta$ gene ( $L V_{\text {PKM }}$-GFP) compared with infusion of GFP alone (LV GFP). No significant differences in any PKC isoforms were found in the PrL. ${ }^{*} p<0.05$. The data are expressed as mean \pm SEM. $n=6-7$ per group.

(BioRad, Hercules, CA, USA). The band intensities from each test sample were compared with the band intensities from the standard curves. The amount of the protein of interest in each sample was interpolated from the standard curve. The standard curve runs in all of the western blots in our study showed that the band intensities for each of our test samples were within the linear range of detection.

\section{Immunohistochemistry}

Immunofluorescence was based on our previous study (Jiang et al, 2013). After the behavioral experiments, the rats were anesthetized and perfused with $0.01 \mathrm{~mol} / \mathrm{l}$ PBS and $4 \%$ paraformaldehyde, $\mathrm{pH}$ 7.4. The brains were then extracted and removed in $4 \%$ paraformaldehyde for $24 \mathrm{~h}$. Subsequently, the brains were placed in $30 \%$ sucrose for $\sim 24-48 \mathrm{~h}$, frozen, coronally sectioned at $10 \mu \mathrm{m}$ using a sliding microtome, and stored in PBS. Brain slices were then mounted on Superfrost/ plus slides, and eGFP expression was screened using a fluorescent microscope at the injection sites. Representative images were captured at the same time.

\section{Statistical Analysis}

Group sizes were balanced to ensure equal variance between the tested groups, and this was verified using Levene's weighted F-test and SPSS software for all comparisons. Each molecular experiment was replicated 2-4 times (an average of three times). All of the data showed a normal distribution and are expressed as mean \pm SEM. The data were analyzed using analysis of variance (ANOVA) with appropriate between-and within-subjects factors for each experiment (see Results). Significant main effects and interactions $(p<0.05$, two-tailed) in the factorial ANOVAs were followed by one-way ANOVAs and the least significant difference post hoc test. 
Timeline

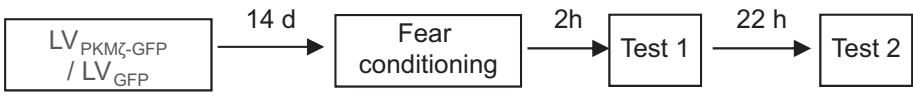

b Intra-PrL infusion of $\mathrm{LV}_{\mathrm{PKM \zeta -GFP}} / \mathrm{LV}_{\mathrm{GFP}}$
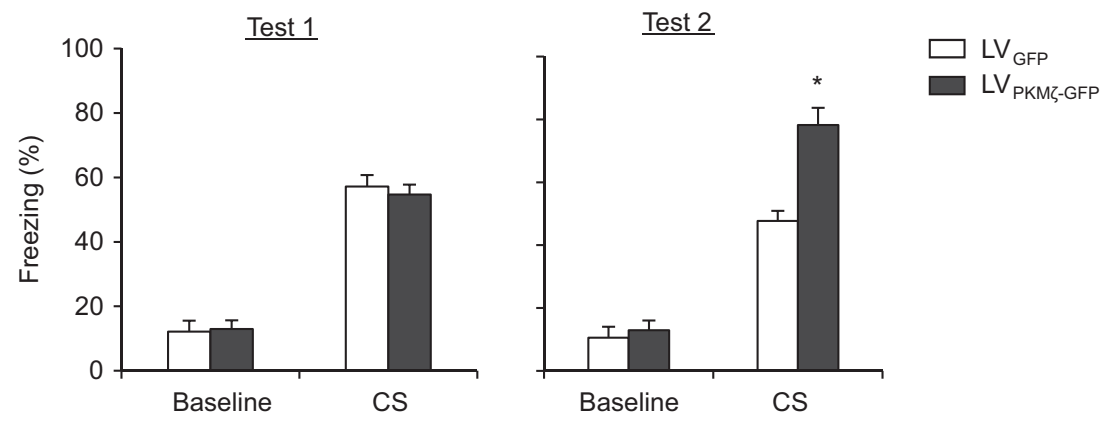

C

Intra-IL infusion of $\mathrm{LV}_{\mathrm{PKM \zeta -GFP}} / \mathrm{LV}_{\mathrm{GFP}}$
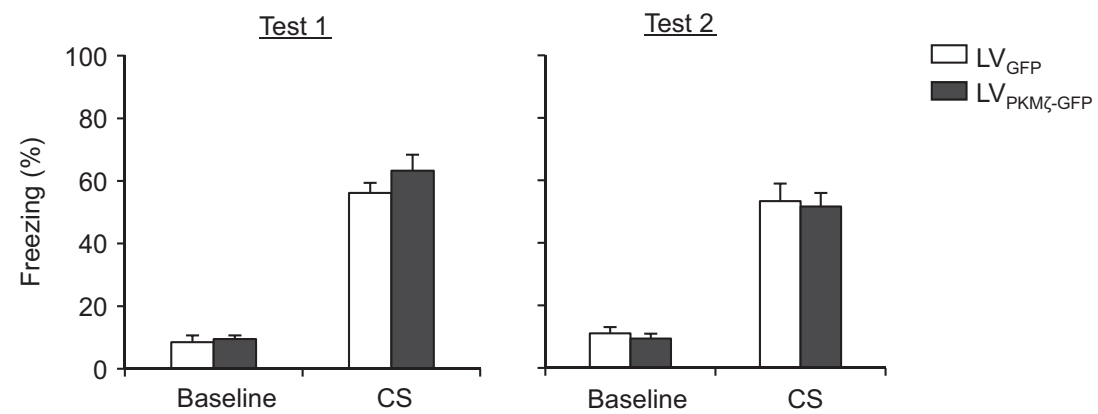

Figure 2 PKM $\zeta$ overexpression in the PrL but not IL enhances the consolidation of fear memory. (a) Timeline of the experiment. One week after $L_{V P K M}$-GFP or LV GFP infusions, all of the rats underwent fear conditioning and were tested for the fear response 2 and $24 \mathrm{~h}$ later. (b) The group that received intra-PrL infusion of LV PKM S-GFP exhibited a significant fear response $24 \mathrm{~h}$ but not $2 \mathrm{~h}$ post-conditioning compared with the LV $V_{\text {PKM }}$-GFP group. (c) The two groups that received infusions in the IL showed similar fear responses in all of the fear tests. $* p<0.05$. The behavioral data are expressed as mean \pm SEM. $n=8-10$ per group.

\section{RESULTS}

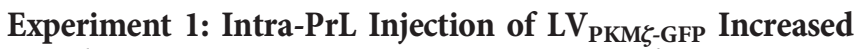 PKM $\zeta$ Protein Levels But Not PKC $\alpha$ or PKC $\lambda$ Levels}

We first constructed and microinjected $\mathrm{LV}_{\mathrm{PKM} \zeta-G F P}$ into the PrL and examined whether $\mathrm{LV}_{\mathrm{PKM} \zeta-\mathrm{GFP}}$ specifically increased the protein expression of $\mathrm{PKM} \zeta$ but not other types of PKC. Two groups of rats ( $n=6-7$ per group) received microinjections of $\mathrm{LV}_{\mathrm{PKM} \zeta-\mathrm{GFP}}$ or $\mathrm{LV}_{\mathrm{GFP}}$. Fourteen days later, all of the rats were euthanized to detect PKC $\alpha$, PKC $\lambda$, and PKM $\zeta$ levels in the PrL.

Figure $1 \mathrm{a}$ and $1 \mathrm{~b}$ show representative pictures of coronal sections of the rat brains with $\mathrm{LV}_{\mathrm{PKM} \zeta-\mathrm{GFP}}$ infusion into the PrL or IL. The analysis of the western blot data using oneway ANOVA revealed that PKM $\zeta$ expression in the PrL was significantly increased 14 days after lentivirus infusion in the group infused with $\mathrm{LV}_{\mathrm{PKM} \zeta-\mathrm{GFP}}$ compared with the group infused with $\mathrm{LV}_{\mathrm{GFP}}$ in the $\operatorname{PrL}\left(F_{1,12}=17.372, p=0.002\right.$; Figure 1c) but not IL $(p>0.05)$. No significant differences were found in the levels of PKC $\alpha$ or PKC $\lambda$ in the PrL (all $p>0.05$; Figure 1c).
Experiment 2: Effect of $\mathrm{PKM} \zeta$ Overexpression in the IL and PrL on Short-Term Memory and Long-Term Memory After Fear Conditioning

We then assessed whether $\mathrm{PKM} \zeta$ overexpression in the PrL and IL enhances the formation of fear memory. Four groups of rats ( $n=8-10$ per group) received $\mathrm{LV}_{\mathrm{PKM} \zeta-\mathrm{GFP}}$ or $\mathrm{LV}_{\mathrm{GFP}}$ infusions into the PrL or IL. Two weeks later, the rats underwent fear conditioning and were tested $2 \mathrm{~h}$ (short-term memory) and $24 \mathrm{~h}$ (long-term memory) later (Figure 2a).

The freezing scores 2 and $24 \mathrm{~h}$ after fear conditioning were analyzed using one-way ANOVA ( $\mathrm{LV}_{\mathrm{PKM} \zeta \text {-GFP }}$ and $\left.\mathrm{LV}_{\mathrm{GFP}}\right)$. This analysis revealed a significant effect of lentivirus type in the PrL $24 \mathrm{~h}$ after fear conditioning $\left(F_{1,17}=20.382, p=0.000\right.$; Figure $2 \mathrm{~b}$, right column) but not $2 \mathrm{~h}$ after fear conditioning ( $p>0.05$; Figure $2 \mathrm{~b}$, left column). In the IL, no significant effect of lentivirus type was found 2 or $24 \mathrm{~h}$ after fear conditioning (all $p>0.05$; Figure $2 c$ ). These data indicate that the overexpression of PKM $\zeta$ in the PrL had no effect on short-term fear memory, but promoted the formation of long-term fear memory. 
Experiment 3: Effect of PKM $\zeta$ Overexpression in the PrL on Locomotor Activity and Anxiety-Like Behavior

In this experiment, we examined whether prelimbic PKM $\zeta$ overexpression affects locomotor activity and anxiety-like behavior. Two groups of rats $(n=8-10$ per group) received $\mathrm{LV}_{\text {PKM }}$-GFP or $\mathrm{LV}_{\mathrm{GFP}}$ infusions in the PrL. Two weeks later, all of the rats underwent the open field and elevated plus maze tests (Figure 3a).

The open field and elevated plus maze data were analyzed using one-way ANOVA ( $\mathrm{LV}_{\mathrm{PKM} \zeta-\mathrm{GFP}}$ and $\left.\mathrm{LV}_{\mathrm{GFP}}\right)$. This analysis revealed no significant effect of lentivirus type on the number of crossings (Figure 3b) or time spent in the central area (Figure 3c) in the open field or time spent on the open arms (Figure 3d) in the elevated plus maze (all $p>0.05$ ). These data indicate that $\mathrm{PKM} \zeta$ overexpression in the PrL had no effect on locomotion or anxiety-like behavior.

\section{Experiment 4: Effect of $\mathrm{PKM} \zeta$ Overexpression on the Membrane Expression of AMPA Receptors in the PrL During the Phases of Short-Term and Long-Term Memory}

AMPA receptor trafficking has been shown to have a role in the involvement of PKM $\zeta$ in LTP and long-term memory (Migues et al, 2010; Yao et al, 2008). We explored the relationship between the membrane expression of AMPA receptors and the enhancing effect of PKM $\zeta$ overexpression on fear memory. Eight groups of rats ( $n=5$ per group) received $L V_{\text {PKM } \zeta-G F P}$ or $L V_{\text {GFP }}$ infusions into the PrL. Two weeks later, the rats were fear-conditioned or exposed to the conditioning chamber without shock. The rats were then decapitated 2 or $24 \mathrm{~h}$ later to assess the membrane expression of GluA1, GluA2, and GluA3 in the PrL (Figure 4a).

The western blot data were analyzed using two-way ANOVA, with conditioning (conditioning and no conditioning) and lentivirus type ( $\mathrm{LV}_{\mathrm{PKM} \zeta-\mathrm{GFP}}$ and $\left.\mathrm{LV}_{\mathrm{GFP}}\right)$ as factors. The analysis of protein levels $2 \mathrm{~h}$ after fear conditioning revealed significant effects of conditioning for GluA1 $\left(F_{1,16}=26.390, p=0.000\right)$ and lentivirus type for GluA2 $\left(F_{1,16}=16.948, p=0.001\right.$; Figure $\left.4 \mathrm{~b}\right)$. The post hoc analysis revealed that the $\mathrm{LV}_{\mathrm{PKM} \zeta \text {-GFP }}+$ fear conditioning and $\mathrm{LV}_{\mathrm{GFP}}+\mathrm{fear}$ conditioning groups exhibited an increase in the membrane levels of GluA1 compared with the other two groups (all $p>0.05$ ). The $\mathrm{LV}_{\mathrm{PKM} \zeta-\mathrm{GFP}}+$ fear conditioning and $\mathrm{LV}_{\mathrm{PKM} \zeta-\mathrm{GFP}}+$ no conditioning groups exhibited an increase in the membrane levels of GluA2 compared with the other two groups. No significant effect of conditioning or lentivirus type on the membrane levels of GluA3 in PrL was found $(p>0.05)$. The analysis of protein levels $24 \mathrm{~h}$ after fear-conditioning revealed significant effects of conditioning $\left(F_{1,16}=13.967, p=0.002\right)$ and lentivirus type $\left(F_{1,17}=10.555\right.$, $p=0.005$; Figure $4 c$ ) for GluA2, and only a significant effect of conditioning on GluAl $\left(F_{1,16}=17.770, p=0.001\right)$ and GluA3 $\left(F_{1,16}=5.613, p=0.03\right)$. The post hoc analysis revealed that the $\mathrm{LV}_{\mathrm{PKM} \zeta-\mathrm{GFP}}+$ fear conditioning and $\mathrm{LV}_{\mathrm{GFP}}+$ fear conditioning groups exhibited an increase in the membrane levels of GluA1 and GluA2 compared with the other two groups (all $p>0.05$ ). The $\mathrm{LV}_{\mathrm{PKM} \zeta \text {-GFP }}$ group exhibited an increase in the membrane levels of GluA2 compared with the other three groups. These data indicate that fear conditioning increased the membrane expression of
GluA1 during the short-term memory phase and increased the membrane expression of GluA1, GluA2, and GluA3 during the long-term memory phase. PKM $\zeta$ overexpression potentiated the fear conditioning-induced increase in the membrane expression of GluA2 during the long-term phase.

\section{DISCUSSION}

In the present study, we evaluated the effect of PKM $\zeta$ overexpression in the $\mathrm{mPFC}$ on the formation of fear memory. We found that microinjection of lentiviral $\mathrm{PKM} \zeta$ GFP selectively enhanced the expression of $\mathrm{PKM} \zeta$ without affecting other forms of PKC. PKM $\zeta$ overexpression in the PrL selectively enhanced the formation of long-term memory but not short-term memory, whereas PKM $\zeta$ overexpression in the IL had no effect on either long-term memory or shortterm memory. The augmenting effect of PKM $\zeta$ overexpression on memory formation did not appear to be attributable to alterations in locomotor activity or the emotional state of the rats because we found that $\mathrm{PKM} \zeta$ overexpression in the PrL had no effect on locomotor activity in the open field or anxiety-like behavior in the elevated plus maze. PKM $\zeta$ overexpression increased the membrane levels of GluA2 and potentiated the increase in the membrane levels of GluA2 induced by fear conditioning. This indicates that PKM $\zeta$ overexpression in the PrL enhanced the formation of longterm fear memory, and this effect may be mediated by elevations of the membrane levels of GluA2 in the PrL.

The PrL and IL are two subregions of the MPFC that have been suggested to have different roles in the formation and expression of fear memory. The activity of PrL neurons is correlated with freezing responses to a CS (Burgos-Robles et al, 2009), and IL neurons fire in response to the CS only when the freezing response is successfully extinguished (Milad and Quirk, 2002). Inactivation of the PrL blocked the acquisition and expression of learned fear (Gilmartin and Helmstetter 2010; Sierra-Mercado et al, 2011), whereas inactivation of the IL impaired the acquisition and recall of extinction (Sierra-Mercado et al, 2011). In addition, cannabinoid, glutamatergic, and dopaminergic signaling regulates the formation and storage of fear memory (Gilmartin and Helmstetter, 2010; Laviolette and Grace, 2006; Runyan and Dash, 2004), whereas dopaminergic, glutamatergic, noradrenergic, and brain-derived neurotrophic factor signaling in the IL modulates the consolidation of extinction of fear memory (Burgos-Robles et al, 2007; Fontanez-Nuin et al, 2011; Mueller et al, 2010; Mueller et al, 2008; Peters et al, 2010). Extending these studies, we found that $\mathrm{PKM} \zeta$ overexpression in the PrL but not IL enhanced the formation of long-term fear memory. The $\mathrm{mPFC}$ has been suggested to participate in the regulation of emotional states (Blanco et al, 2009; Covington et al, 2010; Meloni et al, 2008), which may contribute to the expression of fear (Beracochea et al, 2004; Ferreira and Nobre 2014). We found that $\mathrm{PKM} \zeta$ overexpression in the PrL had no effect on short-term fear memory or anxiety-like behavior, suggesting a selective role for $\mathrm{PKM} \zeta$ in the PrL in the regulation of longterm fear memory.

$\mathrm{PKM} \zeta$, a persistently active PKC isoform, has been shown to be involved in the maintenance of LTP (Ling et al, 2002) and long-term memories, including spatial learning (Pastalkova et al, 2006), auditory fear conditioning 


\section{Timeline}

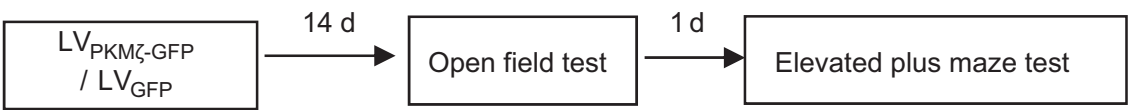

b

\section{Open field test}

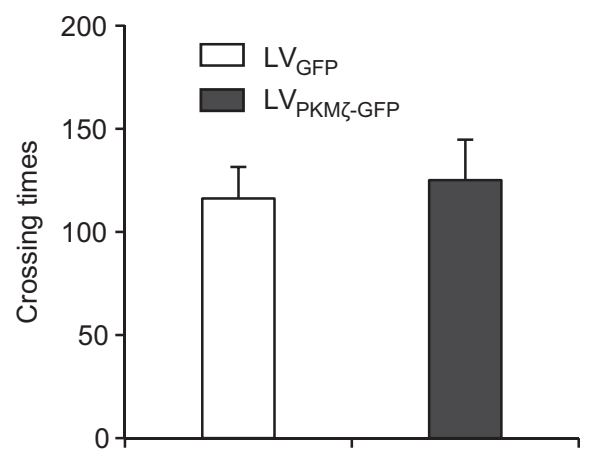

C

\section{Open field test}

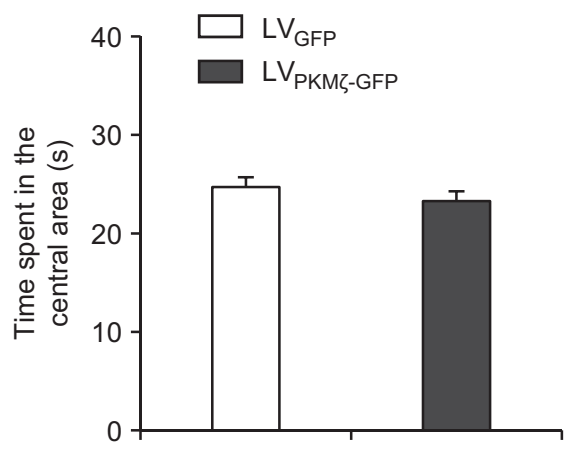

\section{d}

\section{Elevated plus maze test}

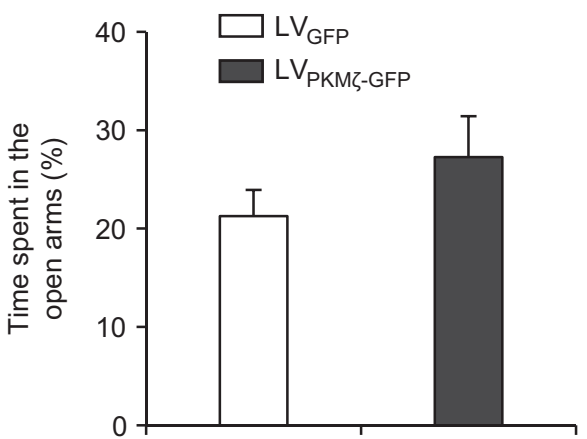

Figure 3 PKM $\zeta$ overexpression in the PrL has no effect on locomotor activity or anxiety-like behavior. (a) Timeline of the experiment. One week after LV PKM -GFP or LV GFP infusions, all of the rats underwent the open field and elevated plus maze tests. (b-d) The two groups exhibited a similar number of crossings (b) and time spent in the central area (c) in the open field and a similar percentage of open arm time (d) in the elevated plus maze. The data are expressed as mean \pm SEM. $n=8-10$ per group.

(Serrano et al, 2008), and conditioned taste aversion (Shema et $a l, 2007)$. We recently found that injections of the PKC $\zeta$ inhibitor ZIP into the nucleus accumbens core disrupted the maintenance of cocaine and morphine reward memory ( $\mathrm{Li}$ et al, 2011). Injections of the PKC $\zeta$ inhibitor ZIP into the infralimbic mPFC abolished the extinction memories of morphine-induced conditioned place preference and conditioned place aversion (He et al, 2011). However, two recent studies reported that $\mathrm{PKM} \zeta$ is not necessary for memory maintenance. Using a global knockout approach that targeted exon 11 of $\mathrm{PKM} \zeta$, Volk et al, (2013) found that LTP induction, the maintenance of fear conditioning, and 
a

Timeline

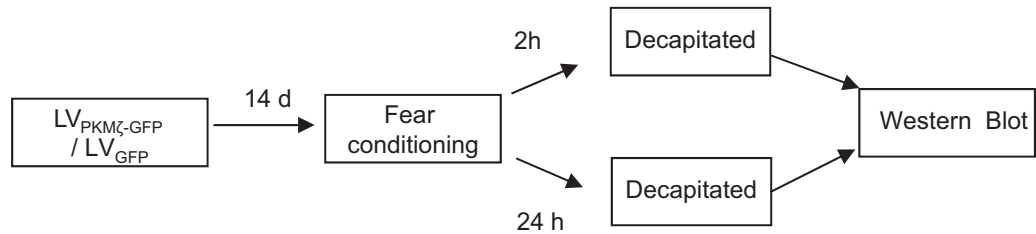

b

Membrane levels of AMPA receptors $2 \mathrm{~h}$ after conditioning

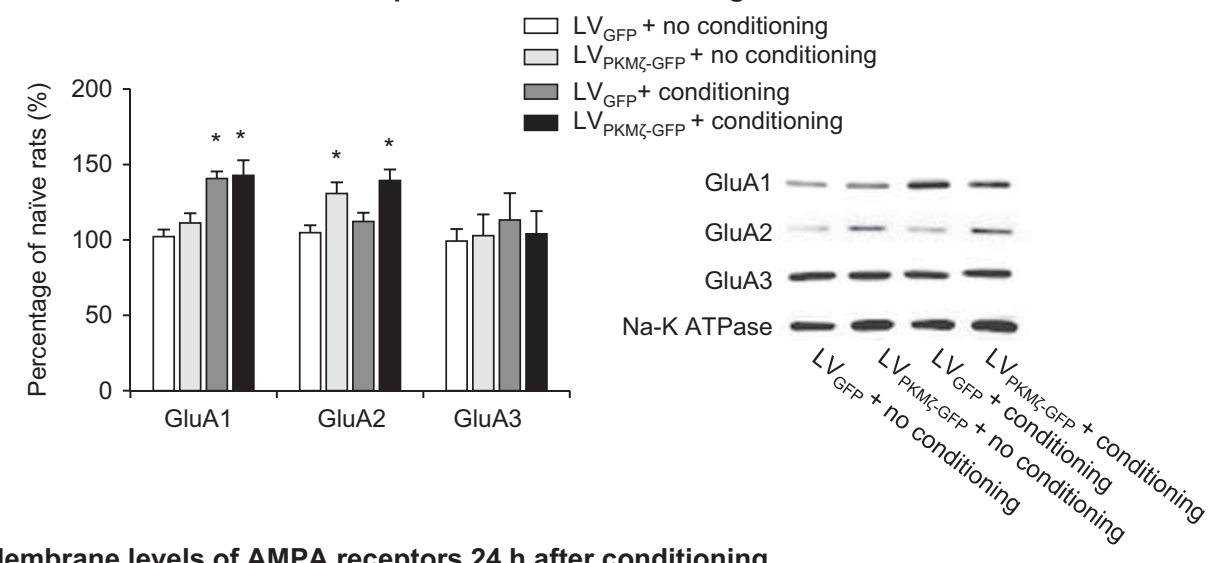

Membrane levels of AMPA receptors $24 \mathrm{~h}$ after conditioning

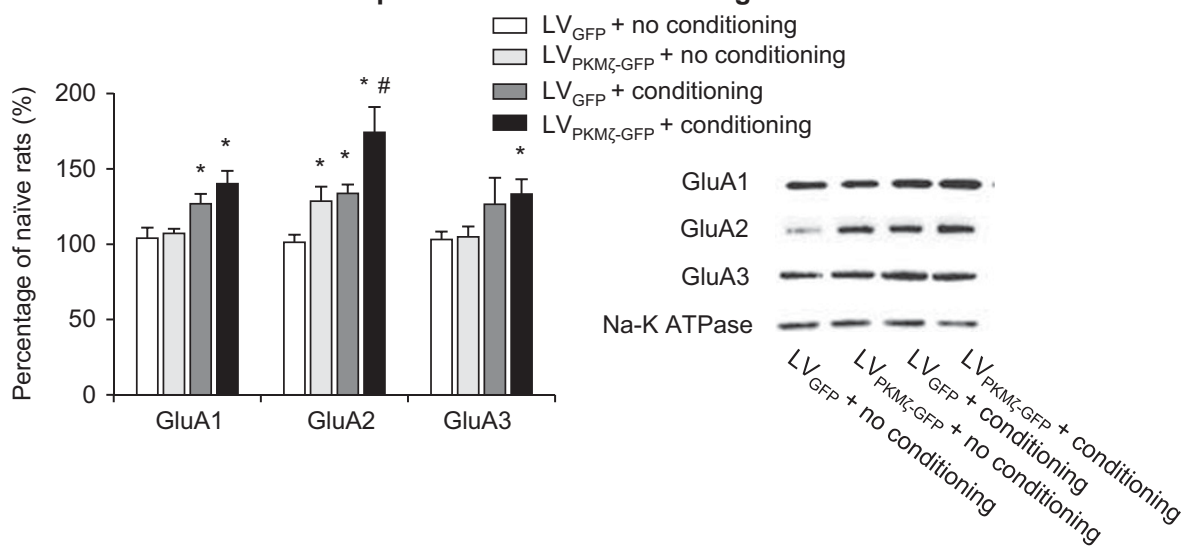

Figure 4 PKM overexpression in the PrL potentiates the fear conditioning-induced increase in membrane GluA2 expression. (a) Timeline of the experiment. One week after $L_{V P K M}$-GFP or LV GFP infusions, all of the rats underwent fear conditioning or exposure to the conditioning chamber. The rats were decapitated for subsequent protein assessment 2 or $24 \mathrm{~h}$ later. (b) Fear conditioning significantly increased the membrane expression of GluAI but not GluA2 or GluA3 during the phase of short-term memory. Intra-PrL infusion of LV PKM૬-GFP significantly increased the membrane expression of GluA2 in the groups with or without fear conditioning. (c) During the phase of long-term memory, fear conditioning significantly increased the membrane expression of GluAI, GluA2, and GluA3, and intra-PrL infusion of LV PKMS-GFP significantly potentiated the increase in the membrane expression of GluA2. * $p<0.05$, compared with $\mathrm{LV}_{\mathrm{GFP}}+$ no conditioning group; ${ }^{\#} p<0.05$, compared with LV PKMY-GFP+no conditioning group. The data are expressed as mean \pm SEM. $n=5$ per group.

spatial memory in the Morris water maze were normal in knockout mice. Lee et al, (2013) similarly observed normal learning and memory, including cued fear conditioning, novel object recognition memory, and cocaine-induced conditioned place preference memory in knockout mice. However, both of these studies used $\mathrm{PKM} \zeta$ knockout animals with disrupted PKM $\zeta$ expression before LTP induction or learning the behavioral task (Lee et al, 2013; Volk et al, 2013). The knockout of PKM $\zeta$ may have triggered compensatory responses that allowed for the normal maintenance of LTP and memory. Although Volk et al, (2013) also used conditional knockout mice, they did not report any behavioral experiments for these mice. Furthermore, a preliminary study from Sacktor's laboratory showed that the constitutive knockout of $\mathrm{PKC} / \mathrm{PKM} \zeta$ resulted in a compensatory increase in phospho-Thr403 $\mathrm{PKCl} / \lambda$ under basal conditions (Tsokas et al, 2012), and $\mathrm{PKCl} / \lambda$ has been shown to be involved in the maintenance of LTP (Ren et al, 2013a). Others also found that ZIP may have an inhibitory effect on PKC $\mathrm{P} / \lambda$ (Ren et al, 2013a), and using $\mathrm{PKM} \zeta$-shRNA to reduce the expression of $\mathrm{PKM} \zeta$ without influencing $\mathrm{PKCl} /$ $\lambda$ abolished the fear memory (Dong et al, 2014). In our 
studies, we used lentiviral vectors to overexpress $\mathrm{PKM} \zeta$, which selectively enhanced the expression of $\mathrm{PKM} \zeta$ without affecting other isoforms of PKC. Notably, in the study by Shema et al, (2011), PKM $\zeta$ was overexpressed after memory formation and enhanced the maintenance of conditioned tasted aversion. In the present study, $\mathrm{PKM} \zeta$ was overexpressed before memory formation and enhanced the formation of long-term memory without influencing shortterm memory. Furthermore, we found that PKM $\zeta$ overexpression potentiated the fear learning-induced increase in the membrane levels of GluA2. Thus, our findings extend Shema's study and suggest that $\mathrm{PKM} \zeta$ overexpression may enhance synaptic plasticity and promote the formation and maintenance of long-term memory. We also found that $\mathrm{PKM} \zeta$ overexpression in the IL had no effect on either shortterm or long-term memory. However, regarding the role of the IL in fear memory (He et al, 2011; Quirk et al, 2006b), further studies are needed to determine the specific effect of $\operatorname{PKM} \zeta$ overexpression on fear extinction and whether there is an optimal balance between PKM $\zeta$ in the PrL and IL to control the expression of fear responses after extinction.

Yao et al, (2008) reported that PKM $\zeta$ modulates late LTP in hippocampal slices, with the involvement of $\mathrm{N}$-ethylmaleimide-sensitive factor (NSF)/GluA2 trafficking. In vivo studies showed that the magnitude of inhibition of fear memories induced by $\mathrm{PKM} \zeta$ inhibition is correlated with the decrease in postsynaptic GluA2. Injection of Tat-GluA2 ${ }_{3 \mathrm{Y}}$, a peptide that inhibits GluA2 endocytosis, prevented the loss of long-term memory induced by both ZIP and lentiviral $\mathrm{PKM} \zeta$ shRNA injections (Dong et al, 2014; Li et al, 2011; Migues et al, 2010). Hara et al, (2012) also found that the synaptic distribution of GluA2 and $\mathrm{PKM} \zeta$ in the monkey dentate gyrus is correlated with long-term memory performance. Extending these findings, we found that $\mathrm{PKM} \zeta$ overexpression increased the membrane expression of GluA2 at baseline and potentiated the fear conditioning-induced increase in GluA2 during the long-term memory phase. In addition, the present study provides in vivo evidence that $\operatorname{PKM} \zeta$ overexpression is sufficient to elicit the distribution of plasticity-related proteins and promote long-term memoryassociated alterations of plasticity-related proteins. Our results are consistent with previous in vitro studies that $\mathrm{PKM} \zeta$ overexpression is sufficient to produce the distribution of GluA2 and postsynaptic density-95 and alterations of the morphology and function of dendrite spines (Ron et al, 2012; Sebastian et al, 2013). However, the conclusion of the causal role of $\mathrm{PKM} \zeta$ in the regulation of GluA2 trafficking during memory consolidation should be made with caution. Memory consolidation has a restricted time-window after memory acquisition (Johansen et al, 2011; McGaugh 2000), while LV-PKM $\zeta$-GFP injections produce a long-lasting $\mathrm{PKM} \zeta$ overexpression. Thus $\mathrm{PKM} \zeta$ overexpression may potentiate the surface expression of GluA2 during the memory consolidation or after memory is consolidated. Fear conditioning induced an additive increase in membrane GluA2, which indicates some other scaffold proteins may regulate AMPAR trafficking during formation of long-term memory. Indeed, it has been demonstrated that NSF, glutamate receptor interacting protein (GRIP) and protein interacting with C-kinase-1 (PICK1), which have critical roles in the trafficking of AMPAR to synapse, are involved in the long-term memory (Carroll et al, 2001;
Cull-Candy et al, 2006; Isaac et al, 2007). Therefore, the causal role of these scaffold proteins in prelimbic cortex in the formation of long-term memory, and their interactions with $\mathrm{PKM} \zeta$ to regulate GluA2 trafficking in cytoplasmic, synaptic and extrasynaptic compartments (Newpher and Ehlers 2008; Opazo and Choquet 2011) should be investigated in the future studies.

\section{CONCLUDING REMARKS}

In summary, we found that $\mathrm{PKM} \zeta$ overexpression in the PrL but not IL enhanced the formation of fear memory, and $\mathrm{PKM} \zeta$ in the PrL may contribute to the formation of longterm fear memory. The effect of $\mathrm{PKM} \zeta$ overexpression on memory formation was not attributable to alterations in locomotor activity or the emotional state of rats. The potentiating effect of $\mathrm{PKM} \zeta$ overexpression on long-term memory may be mediated by the promotion of membrane GluA2 expression. The present study extends our understanding of the role of $\mathrm{PKM} \zeta$ in learning and memory and related neurological disorders.

\section{FUNDING AND DISCLOSURE}

This work was supported in part by the 973 program (No. 2015CB856400, 2015CB553503 and 2015CB559200) and Natural Science Foundation of China (No. 81271525, 91132716, 31230033, 81221002, 81201032, 31300930). The authors declare no conflict of interest.

\section{REFERENCES}

Bannerman DM, Rawlins JN, McHugh SB, Deacon RM, Yee BK, Bast T et al (2004). Regional dissociations within the hippocampus-memory and anxiety. Neurosci Biobehav Rev 28: 273-283.

Beracochea D, Celerier A, Pierard C (2004). BetaCCM but not physostigmine enhancement of memory retrieval depends on emotional processes in mice. Psychopharmacology (Berl) 176: 66-73.

Blanco E, Castilla-Ortega E, Miranda R, Begega A, Aguirre JA, Arias JL et al (2009). Effects of medial prefrontal cortex lesions on anxiety-like behaviour in restrained and non-restrained rats. Behav Brain Res 201: 338-342.

Burgos-Robles A, Vidal-Gonzalez I, Quirk GJ (2009). Sustained conditioned responses in prelimbic prefrontal neurons are correlated with fear expression and extinction failure. $J$ Neurosci 29: 8474-8482.

Burgos-Robles A, Vidal-Gonzalez I, Santini E, Quirk GJ (2007). Consolidation of fear extinction requires NMDA receptordependent bursting in the ventromedial prefrontal cortex. Neuron 53: 871-880.

Carroll RC, Beattie EC, von Zastrow M, Malenka RC (2001). Role of AMPA receptor endocytosis in synaptic plasticity. Nat Rev Neurosci 2: 315-324.

Corcoran KA, Quirk GJ (2007). Activity in prelimbic cortex is necessary for the expression of learned, but not innate, fears. J Neurosci 27: 840-844.

Covington HE 3rd, Lobo MK, Maze I, Vialou V, Hyman JM, Zaman S et al (2010). Antidepressant effect of optogenetic stimulation of the medial prefrontal cortex. J Neurosci 30: 16082-16090.

Cull-Candy S, Kelly L, Farrant M (2006). Regulation of Ca2+-permeable AMPA receptors: synaptic plasticity and beyond. Curr Opin Neurobiol 16: 288-297. 
Dong Z, Han H, Li H, Bai Y, Wang W, Tu M et al (2014). Longterm potentiation decay and memory loss are mediated by AMPAR endocytosis. J Clin Invest 125: 234-247.

Duvarci S, Pare D (2014). Amygdala microcircuits controlling learned fear. Neuron 82: 966-980.

Evuarherhe O, Barker GR, Savalli G, Warburton EC, Brown MW (2014). Early memory formation disrupted by atypical PKC inhibitor ZIP in the medial prefrontal cortex but not hippocampus. Hippocampus 24: 934-942.

Fanselow MS, Gale GD (2003). The amygdala, fear, and memory. Ann N Y Acad Sci 985: 125-134.

Ferreira R, Nobre MJ (2014). Conditioned fear in low- and highanxious rats is differentially regulated by cortical subcortical and midbrain 5-HT(1A) receptors. Neuroscience 268: 159-168.

Fontanez-Nuin DE, Santini E, Quirk GJ, Porter JT (2011). Memory for fear extinction requires mGluR5-mediated activation of infralimbic neurons. Cereb Cortex 21: 727-735.

Gilmartin MR, Balderston NL, Helmstetter FJ (2014). Prefrontal cortical regulation of fear learning. Trends Neurosci 37: 455-464.

Gilmartin MR, Helmstetter FJ (2010). Trace and contextual fear conditioning require neural activity and NMDA receptordependent transmission in the medial prefrontal cortex. Learn Mem 17: 289-296.

Goosens KA (2011). Hippocampal regulation of aversive memories. Curr Opin Neurobiol 21: 460-466.

Guhn A, Dresler T, Andreatta M, Muller LD, Hahn T, Tupak SV et al (2014). Medial prefrontal cortex stimulation modulates the processing of conditioned fear. Front Behav Neurosci 8: 44.

Hara Y, Punsoni M, Yuk F, Park CS, Janssen WG, Rapp PR et al (2012). Synaptic distributions of GluA2 and PKMzeta in the monkey dentate gyrus and their relationships with aging and memory. $J$ Neurosci 32: 7336-7344.

He YY, Xue YX, Wang JS, Fang Q, Liu JF, Xue LF et al (2011). PKMzeta maintains drug reward and aversion memory in the basolateral amygdala and extinction memory in the infralimbic cortex. Neuropsychopharmacology 36: 1972-1981.

Heidbreder CA, Groenewegen HJ (2003). The medial prefrontal cortex in the rat: evidence for a dorso-ventral distinction based upon functional and anatomical characteristics. Neurosci Biobehav Rev 27: 555-579.

Hylin MJ, Orsi SA, Moore AN, Dash PK (2013). Disruption of the perineuronal net in the hippocampus or medial prefrontal cortex impairs fear conditioning. Learn Mem 20: 267-273.

Isaac JT, Ashby MC, McBain CJ (2007). The role of the GluR2 subunit in AMPA receptor function and synaptic plasticity. Neuron 54: 859-871.

Jiang WG, Li SX, Liu JF, Sun Y, Zhou SJ, Zhu WL et al (2013). Hippocampal CLOCK protein participates in the persistence of depressive-like behavior induced by chronic unpredictable stress. Psychopharmacology (Berl) 227: 79-92.

Johansen JP, Cain CK, Ostroff LE, LeDoux JE (2011). Molecular mechanisms of fear learning and memory. Cell 147: 509-524.

Kwapis JL, Helmstetter FJ (2014). Does PKM(zeta) maintain memory? Brain Res Bull 105: 36-45.

Laviolette SR, Grace AA (2006). Cannabinoids potentiate emotional learning plasticity in neurons of the medial prefrontal cortex through basolateral amygdala inputs. J Neurosci 26: 6458-6468.

LeDoux JE (2000). Emotion circuits in the brain. Annu Rev Neurosci 23: $155-184$

Lee AM, Kanter BR, Wang D, Lim JP, Zou ME, Qiu C et al (2013). Prkcz null mice show normal learning and memory. Nature 493: 416-419.

Lee YK, Choi JS (2012). Inactivation of the medial prefrontal cortex interferes with the expression but not the acquisition of differential fear conditioning in rats. Exp Neurobiol 21: 23-29.

Li YQ, Xue YX, He YY, Li FQ, Xue LF, Xu CM et al (2011). Inhibition of PKMzeta in nucleus accumbens core abolishes longterm drug reward memory. J Neurosci 31: 5436-5446.
Ling DS, Benardo LS, Serrano PA, Blace N, Kelly MT, Crary JF et al (2002). Protein kinase Mzeta is necessary and sufficient for LTP maintenance. Nat Neurosci 5: 295-296.

Maren S (2003). The amygdala, synaptic plasticity, and fear memory. Ann N Y Acad Sci 985: 106-113.

Maren S, Phan KL, Liberzon I (2013). The contextual brain: implications for fear conditioning, extinction and psychopathology. Nat Rev Neurosci 14: 417-428.

Maren S, Quirk GJ (2004). Neuronal signalling of fear memory. Nat Rev Neurosci 5: 844-852.

McGaugh JL (2000). Memory-a century of consolidation. Science 287: 248-251.

Meloni EG, Reedy CL, Cohen BM, Carlezon WA Jr. (2008). Activation of raphe efferents to the medial prefrontal cortex by corticotropin-releasing factor: correlation with anxiety-like behavior. Biol Psychiatry 63: 832-839.

Migues PV, Hardt O, Wu DC, Gamache K, Sacktor TC, Wang YT et al (2010). PKMzeta maintains memories by regulating GluR2dependent AMPA receptor trafficking. Nat Neurosci 13: 630-634.

Milad MR, Quirk GJ (2002). Neurons in medial prefrontal cortex signal memory for fear extinction. Nature 420: 70-74.

Milad MR, Wright CI, Orr SP, Pitman RK, Quirk GJ, Rauch SL (2007). Recall of fear extinction in humans activates the ventromedial prefrontal cortex and hippocampus in concert. Biol Psychiatry 62: 446-454.

Monfils MH, Cowansage KK, Klann E, LeDoux JE (2009). Extinction-reconsolidation boundaries: key to persistent attenuation of fear memories. Science 324: 951-955.

Mueller D, Bravo-Rivera C, Quirk GJ (2010). Infralimbic D2 receptors are necessary for fear extinction and extinction-related tone responses. Biol Psychiatry 68: 1055-1060.

Mueller D, Porter JT, Quirk GJ (2008). Noradrenergic signaling in infralimbic cortex increases cell excitability and strengthens memory for fear extinction. J Neurosci 28: 369-375.

Newpher TM, Ehlers MD (2008). Glutamate receptor dynamics in dendritic microdomains. Neuron 58: 472-497.

Opazo P, Choquet D (2011). A three-step model for the synaptic recruitment of AMPA receptors. Mol Cell Neurosci 46: 1-8.

Pastalkova E, Serrano P, Pinkhasova D, Wallace E, Fenton AA, Sacktor TC (2006). Storage of spatial information by the maintenance mechanism of LTP. Science 313: 1141-1144.

Paxinos G, Watson C (2005). The Rat Brain In Stereotaxic Coordinates, 5 edn. Elsevier Academic Press: Amsterdam.

Peters J, Dieppa-Perea LM, Melendez LM, Quirk GJ (2010). Induction of fear extinction with hippocampal-infralimbic BDNF. Science 328: 1288-1290.

Quirk GJ, Beer JS (2006). Prefrontal involvement in the regulation of emotion: convergence of rat and human studies. Curr Opin Neurobiol 16: 723-727.

Quirk GJ, Garcia R, Gonzalez-Lima F (2006). Prefrontal mechanisms in extinction of conditioned fear. Biol Psychiatry 60: 337-343.

Reis DS, Jarome TJ, Helmstetter FJ (2013). Memory formation for trace fear conditioning requires ubiquitin-proteasome mediated protein degradation in the prefrontal cortex. Front Behav Neurosci 7: 150

Ren SQ, Yan JZ, Zhang XY, Bu YF, Pan WW, Yao W et al (2013). PKClambda is critical in AMPA receptor phosphorylation and synaptic incorporation during LTP. EMBO J 32: 1365-1380.

Ren ZY, Liu MM, Xue YX, Ding ZB, Xue LF, Zhai SD et al (2013). A critical role for protein degradation in the nucleus accumbens core in cocaine reward memory. Neuropsychopharmacology 38: 778-790.

Riccio DC, Joynes RL (2007). Forgetting of stimulus attributes: some implications for hippocampal models of memory. Learn Mem 14: 430-432.

Ron S, Dudai Y, Segal M (2012). Overexpression of PKMzeta alters morphology and function of dendritic spines in cultured cortical neurons. Cereb Cortex 22: 2519-2528. 
Runyan JD, Dash PK (2004). Intra-medial prefrontal administration of SCH-23390 attenuates ERK phosphorylation and long-term memory for trace fear conditioning in rats. Neurobiol Learn Mem 82: 65-70.

Sacktor TC (2008). PKMzeta, LTP maintenance, and the dynamic molecular biology of memory storage. Prog Brain Res 169: 27-40.

Sebastian V, Estil JB, Chen D, Schrott LM, Serrano PA (2013). Acute physiological stress promotes clustering of synaptic markers and alters spine morphology in the hippocampus. PLoS One 8: e79077.

Serrano P, Friedman EL, Kenney J, Taubenfeld SM, Zimmerman JM, Hanna J et al (2008). PKMzeta maintains spatial, instrumental, and classically conditioned long-term memories. PLoS Biol 6: 2698-2706.

Shema R, Haramati S, Ron S, Hazvi S, Chen A, Sacktor TC et al (2011). Enhancement of consolidated long-term memory by overexpression of protein kinase Mzeta in the neocortex. Science 331: 1207-1210.

Shema R, Sacktor TC, Dudai Y (2007). Rapid erasure of long-term memory associations in the cortex by an inhibitor of PKM zeta. Science 317: 951-953.

Shi HS, Zhu WL, Liu JF, Luo YX, Si JJ, Wang SJ et al (2012). PI3K/ Akt signaling pathway in the basolateral amygdala mediates the rapid antidepressant-like effects of trefoil factor 3. Neuropsychopharmacology 37: 2671-2683.

Si J, Yang J, Xue L, Yang C, Luo Y, Shi H et al (2012). Activation of NF-kappaB in basolateral amygdala is required for memory reconsolidation in auditory fear conditioning. PLoS One 7: e43973.

Sierra-Mercado D, Padilla-Coreano N, Quirk GJ (2011). Dissociable roles of prelimbic and infralimbic cortices, ventral hippocampus, and basolateral amygdala in the expression and extinction of conditioned fear. Neuropsychopharmacology 36: 529-538.

Sotres-Bayon F, Quirk GJ (2010). Prefrontal control of fear: more than just extinction. Curr Opin Neurobiol 20: 231-235.
Sotres-Bayon F, Sierra-Mercado D, Pardilla-Delgado E, Quirk GJ (2012). Gating of fear in prelimbic cortex by hippocampal and amygdala inputs. Neuron 76: 804-812.

Suo L, Zhao L, Si J, Liu J, Zhu W, Chai B et al (2013). Predictable chronic mild stress in adolescence increases resilience in adulthood. Neuropsychopharmacology 38: 1387-1400.

Tsokas P, Hsieh C, Wallace ECJ, Cottrell JE, Fenton AA, Messing RO et al (2012). Conditional knockout of the PKC/PKM $\zeta$ gene in the adult mouse hippocampus prevents L-LTP Society for Neuroscience Annual Meeting. New Orleans, LA.

Vidal-Gonzalez I, Vidal-Gonzalez B, Rauch SL, Quirk GJ (2006). Microstimulation reveals opposing influences of prelimbic and infralimbic cortex on the expression of conditioned fear. Learn Mem 13: 728-733.

Volk LJ, Bachman JL, Johnson R, Yu Y, Huganir RL (2013). PKMzeta is not required for hippocampal synaptic plasticity, learning and memory. Nature 493: 420-423.

Xue YX, Luo YX, Wu P, Shi HS, Xue LF, Chen C et al (2012). A memory retrieval-extinction procedure to prevent drug craving and relapse. Science 336: 241-245.

Xue YX, Xue LF, Liu JF, He J, Deng JH, Sun SC et al (2014). Depletion of perineuronal nets in the amygdala to enhance the erasure of drug memories. J Neurosci 34: 6647-6658.

Yang C, Liu JF, Chai BS, Fang Q, Chai N, Zhao LY et al (2013). Stress within a restricted time window selectively affects the persistence of long-term memory. PLoS One 8: e59075.

Yao Y, Kelly MT, Sajikumar S, Serrano P, Tian D, Bergold PJ et al (2008). PKM zeta maintains late long-term potentiation by N-ethylmaleimide-sensitive factor/GluR2-dependent trafficking of postsynaptic AMPA receptors. J Neurosci 28: 7820-7827.

Zhu WL, Shi HS, Wang SJ, Xu CM, Jiang WG, Wang X et al (2012). Increased Cdk5/p35 activity in the dentate gyrus mediates depressive-like behaviour in rats. Int J Neuropsychopharmacol 15: 795-809. 